\title{
Ultra-high strain in epitaxial silicon carbide nanostructures utilizing residual stress amplification
}

\author{
Hoang-Phuong Phan, ${ }^{1}$ a) Tuan-Khoa Nguyen, ${ }^{1}$ Toan Dinh, ${ }^{1}$ Ginnosuke Ina, ${ }^{2}$ Atieh Ranjbar Kermany, ${ }_{1}^{1}$ Afzaal \\ Qamar, ${ }^{1}$ Jisheng Han, ${ }^{1}$ Takahiro Namazu, ${ }^{3}$ Ryutaro Maeda, ${ }^{4}$ Dzung Viet Dao, ${ }^{1}$ and Nam-Trung Nguyen ${ }^{1}$ \\ 1) Queensland Micro and Nanotechnology Centre, Griffith University, QlD, 4111, \\ Australia. \\ ${ }^{2)}$ Department of Mechanical Engineering, University of Hyogo, Hyogo,671-2280, \\ Japan. \\ 3) Department of Mechanical Engineering, Aichi Institute of Technology, Toyota, 470-0392, \\ Japan. \\ ${ }^{4)}$ National Institute of Advanced Industrial Science and Technology (AIST), Tsukuba, Ibaraki, 305-8560, \\ Japan.
}

(Dated: 20 March 2017)

\begin{abstract}
Strain engineering has attracted great attention, particularly for epitaxial films grown on a different substrate. Residual strains of $\mathrm{SiC}$ have been widely employed to form ultra-high frequency and high $\mathrm{Q}$ factor resonators. However, to date the highest residual strain of $\mathrm{SiC}$ was reported to be limited to approximately $0.6 \%$. Large strains induced into $\mathrm{SiC}$ could lead to several interesting physical phenomena, as well as significant improvement of resonant frequencies. We report an unprecedented nano strain-amplifier structure with an ultra-high residual strain up to $8 \%$ utilizing the natural residual stress between epitaxial 3C-SiC and Si. In addition, the applied strain can be tuned by changing the dimensions of the amplifier structure. The possibility of introducing such a controllable and ultra-high strain will open the door to investigating the physics of $\mathrm{SiC}$ in large strain regimes, and the development of ultra sensitive mechanical sensors.
\end{abstract}

Strain engineering plays an important role in electronic devices $^{1,2}$. For instance, in complementary metal oxide semiconductor (CMOS) technology, scaling down the device to sub $100 \mathrm{~nm}$ regime encounters several challenges due to the degradation of carrier mobility ${ }^{3,4}$. To enhance the performance of silicon CMOS with shrinking size, the introduction of strain into Si channel has been a key concept to compensate the decrease in carrier mobility $^{5-7}$. In addition, micro/nano electromechanical systems (MEMS/NEMS) have also benefited from strain engineering where the residual strain was applied between epilayers to enhance the resonant frequency $(f)$ and the quality $(Q)$ factor following Euler-Bernoulli theory ${ }^{8}$.

Silicon carbide, a wide band gap material, has showed its high potential in MEMS/NEMS applications ${ }^{9,10}$. The large band gap makes $\mathrm{SiC}$ an excellent candidate for high temperature electronics applications where Si has limitation. The large Young's modulus of above $300 \mathrm{GPa}$ offers $\mathrm{SiC}$ resonators higher resonant frequencies in comparison to $\mathrm{Si}$ based counterparts ${ }^{11,12}$. Other physical properties such as the piezoresistive effect and the thermoresistive effect in $\mathrm{SiC}$ have also been employed to develop mechanical and thermal sensors for structural health monitoring $(\mathrm{SHM})^{13-20}$. Cubic $\mathrm{SiC}(3 \mathrm{C}-\mathrm{SiC})$ is the only polytype, among over $200 \mathrm{SiC}$ polytypes, that can be grown (epitaxially) on Si substrate and thus is the most suitable polytype for MEMS/NEMS applications ${ }^{9,21}$. This allows the reduction of $\mathrm{SiC} / \mathrm{Si}$ wafer cost as well as makes it compatible with the conventional micromachining process developed for $\mathrm{Si}$. The epitaxial growth of $\mathrm{SiC}$ on $\mathrm{Si}$ further results in a large residual stress within the $\mathrm{SiC}$ film due to the lattice and thermal mismatches between the $\mathrm{SiC}$ film and the Si substrate ${ }^{22}$. This residual stress can be potentially

\footnotetext{
a)Electronic mail: hoangphuong.phan@griffithuni.edu.au
}

applied to enhance the $f \times Q$ of the resonators. Resonators with high frequencies up to several $\mathrm{GHz}$ and $f \times Q$ factors up to $10^{11}$ have been developed through the application of residual stress ${ }^{22-24}$.

In most previous studies, the maximum strain induced into $\mathrm{SiC}$ ranged from $0.1 \%$ to $0.6 \%^{27-30}$. It should be noted that the larger strain is induced, the higher resonant frequency can be achieved. In addition, large strains up to $10 \%$ could also lead to several significant changes in electrical/optical properties, which have been observed in several materials ${ }^{31,32}$. A large stress could also cause unintended properties such as wafer bow and cracks, making the realization of ultra-high strain in $\mathrm{SiC}$ a challenging issue. Therefore, in order to make extremely high strain in $\mathrm{SiC}$ possible, it is important to locally amplify strain in a specific area, while keeping the strain in the other parts of the film in a relatively small regime.

We propose here a method to induce extremely high strain into $\mathrm{SiC}$ by using a nano strain-amplifier. For the proof of concept, we demonstrate the feasibility of introducing a strain of approximately $8 \%$ into a $\mathrm{SiC}$ nano-spring structure, which is at least one order of magnitude larger than that reported in the literature. The possibility of inducing such a high strain will pave the path for experimental investigations of the physics of $\mathrm{SiC}$ in high strain regimes as well as for the development of highly sensitive $\mathrm{SiC}$ sensors. Our methodology should also be applicable for not only $\mathrm{SiC}$ but other materials including graphene and transition metal dichalcogenides (TMD), where high strain regimes are of significant interest.

Figure 1(a) illustrates the basic concept to induce large strain into $\mathrm{SiC}$ devices. The nano strain-amplifier consists of a $\mathrm{SiC}$ micro bridge which is released from a Si substrate, and a modified area which is located at the centre of the bridge. In addition, the modified area is designed to exhibit a smaller stiffness in comparison to the remaining areas of the $\mathrm{SiC}$ bridge. To soften this modified area, the following 
(a) Concept

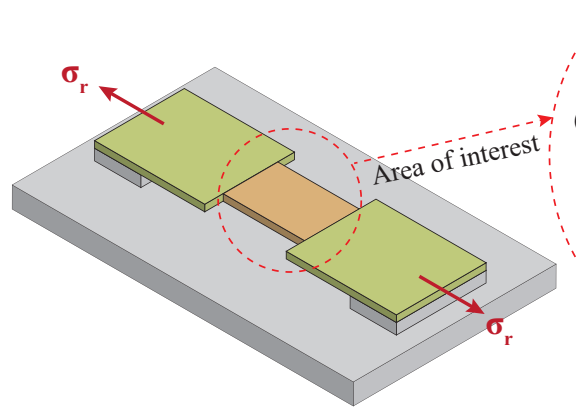

(b) Stress relaxation

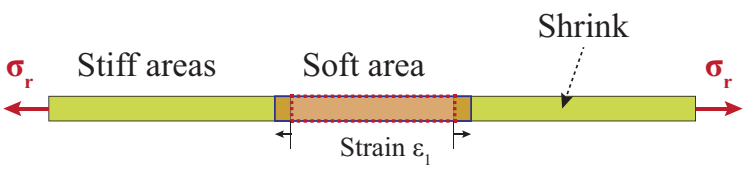

(c) Stress gradient

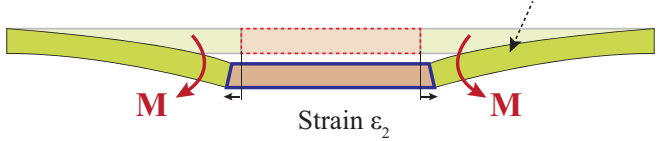

Total strain $\varepsilon=\varepsilon_{1}+\varepsilon_{2}$

FIG. 1. (a) Concept of devices to induce large strain into interested area; (b)(c) Principle of the nano strain-amplifier based on planar residual stress and stress gradient (side-view sketch).

techniques can be utilized. First, the width of the middle area can be shrunk down to nanometer scale so that the ratio of the stiffness between the nanowire and micro-frame is significantly diminished. Second, the middle section can be softened by modifying its structure; as such a nano-spring can offer much larger elongation than that of a nano rod with the same dimension. Furthermore, by changing material from single-crystalline to amorphous, it is also possible to tune the stiffness of a specific region ${ }^{25,26}$. In the subsequent experiment, we selected the structure modification approach to form the soft area, as it can provide large elongation which eases the strain observation using scanning electron microscopy (SEM).

The key finding of our structure is that the low stiffness of the modified nano-area allows it to follow the deformation of the serially connected micro structures. As 3C-SiC has a smaller lattice size than $\mathrm{Si}$, the $\mathrm{SiC}$ film typically undergoes a considerable tensile stress when being epitaxially grown on the $\mathrm{Si}$ substrate. When a $\mathrm{SiC}$ bridge is released, its lattice constant tends to return to its original size, which subsequently shrinks the size of the bridge. Because this phenomenon is more dominant in the $\mathrm{SiC}$ micro-areas, the nano-are will be stressed following the motion of these micro-area, Fig. 1(b). Furthermore, in a epitaxial film, large stresses typically distribute near the interface between top layer and the substrate. The residual stress gradually decreases with increasing film thickness or even relax for sufficiently thick films. This variation of the residual stress will cause a stress gradient along the thickness dimension, resulting in a bending moment once the film is suspended from the substrate. Therefore, under
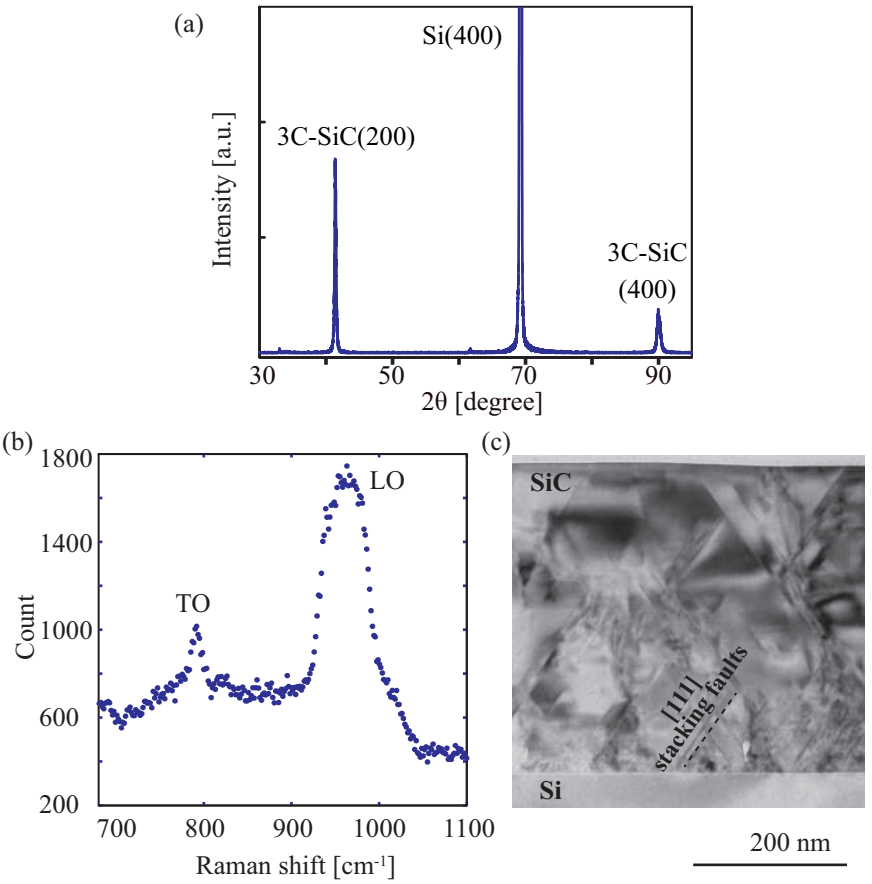

FIG. 2. Properties of the SiC films. (a) X-Ray Diffraction; (b) Raman spectroscopy; (c) Transmission electron microscopy.

the residual bending moment, the micro-frames will deflect vertically, leading to an elongation in the softened nanoarea, Fig. 1(c). Combining the two phenomena of in-plane shrinking and out-of-plane deflection, an ultra-high strain is expected to be induced into the $\mathrm{SiC}$ nano structures.

The $\mathrm{SiC}$ film was prepared on a $\mathrm{Si}$ (100) wafer using low pressure chemical vapor deposition (CVD) where silane $\left(\mathrm{SiH}_{4}\right)$ and propylene $\left(\mathrm{C}_{3} \mathrm{H}_{6}\right)$ were employed as the precursors $^{35}$. As aforementioned, $\mathrm{SiC}$ and Si have significant lattice and thermal expansion mismatch of $\sim 20 \%$ and $\sim 8 \%$ respectively. The growth temperature was kept at $1000^{\circ} \mathrm{C}$ utilizing alternating supply epitaxy (ASE) approach. X-Ray Diffraction (XRD) method was utilized to investigate the crystallinity of the $\mathrm{SiC}$ film. Figure 2(a) shows diffraction peaks at $35.6^{\circ}$ and $90^{\circ}$, corresponding to $3 \mathrm{C}-\mathrm{SiC}(200)$ and $3 \mathrm{C}-\mathrm{SiC}(400)$ orientations. In addition, besides these two peaks, only a peak at $69.1^{\circ}$ was observed, corresponding to $\mathrm{Si}(400)$. This result indicated that single crystalline 3C-SiC (100) was grown on a Si substrate. The thickness of the films was found to be $294 \mathrm{~nm}$ using NANOMETRICS Nanospec/AFT 210.

The Raman scattering measurement was performed using ${ }^{\mathrm{TM}}$ Renishaw inVia Raman microscopy $514 \mathrm{~nm}$ wavelength, Fig .2(b). The peak observed at $794 \mathrm{~cm}^{-1}$ corresponds to the transverse optical (TO) vibration of $3 \mathrm{C}-\mathrm{SiC}$. Our TO peak was relatively smaller than that of stress-free $3 \mathrm{C}-\mathrm{SiC}$ which was reported to be $795.9 \mathrm{~cm}^{-1}$. Therefore, the left shift of the TO peak indicates the existence of a tensile stress in the epitaxial $3 \mathrm{C}-\mathrm{SiC}$ film. The average tensile strain $\left(\varepsilon_{r}\right)$ in the $\mathrm{SiC}$ film can be quantified using the coefficient reported by Rohmfeld et al. ${ }^{27}$ :

$$
\frac{\omega_{T O}}{\mathrm{~cm}^{-1}}=(795.9 \pm 0.1)-(1125 \pm 20) \varepsilon_{r}
$$

Consequently, the average strain induced into the as- 
deposited SiC film was approximately $0.16 \%$ to $0.2 \%$, which was in the same range with other epitaxial 3C-SiC film reported previously. Once the $\mathrm{SiC}$ bridge was suspended, the residual stress was released and $\mathrm{SiC}$ tended to return to its stress-free state. Furthermore, as the $\mathrm{SiC}$ micro frames are much harder than the nano-spring (or other nano structures) located at the centre, the shrink of these frames are much more dominant. Assuming that the micro frames completely shrink down to their strain-free state, the strain induced into the nano-spring $\left(\varepsilon_{n s}\right)$ can be approximated using the following equation:

$$
\varepsilon_{n s}=\frac{L_{f}}{L_{n s}} \varepsilon_{r}
$$

where $L_{f}$ and $L_{n s}$ are the length of the frame and the nano-spring, respectively.

Additionally, the quality of the $\mathrm{SiC}$ film was characterized using transmission electron microscopy (TEM). The TEM image shown in Fig .2(c) indicates a high density of defects near the $\mathrm{SiC} / \mathrm{Si}$ interface. Most defects were found to be stacking faults in [111] crystallographic orientation due to the lattice mismatch between $\mathrm{SiC}$ and $\mathrm{Si}$. Quality of the $\mathrm{SiC}$ film was evidently improved with increasing film thickness, exhibiting less crystal defect on the top layers. This observation also indicates a stress gradient through out the film. As such, in our previous report, a large stress was observed in the bottom layers of 3C-SiC (100) films, while the stress decreased or relaxed at layers near the top surface $^{34}$. The bending moment exerted on $\mathrm{SiC}$ can be estimated from the Young's modulus of $\mathrm{SiC}$ and the deflection of free standing $\mathrm{SiC}$ cantilevers. Accordingly, the deflection $(\delta)$ of a suspended $\mathrm{SiC}$ cantilever is given by:

$$
\delta=\frac{M l^{2}}{2 E I}
$$

where $M$ is the bending moment; and $l, E$ and $I$ are the length, Young's modulus, and moment of inertia of the

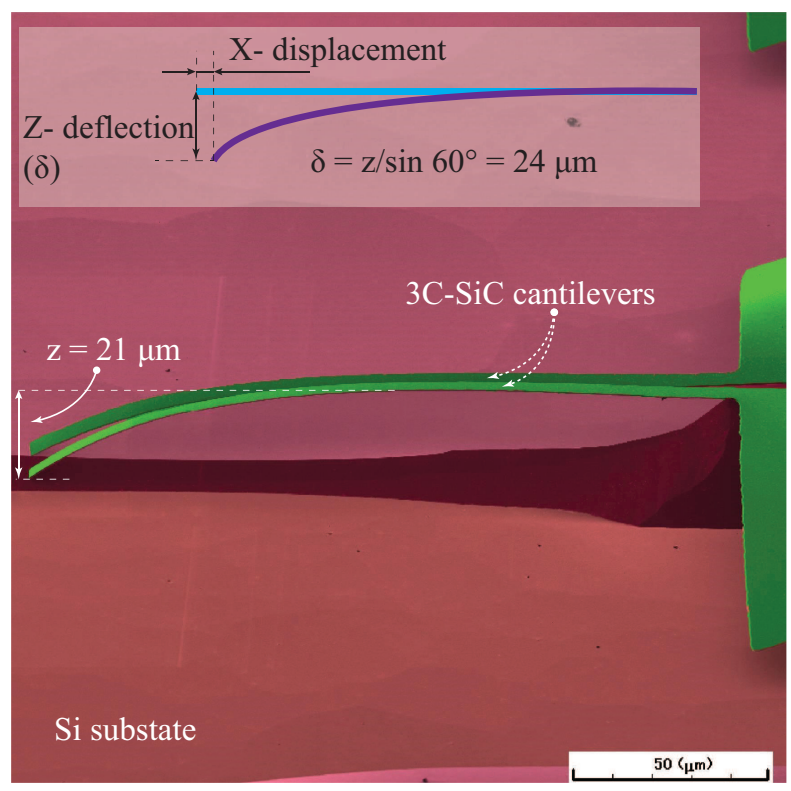

FIG. 3. Observation of the out-of-plane deflection in a released 3C-SiC cantilever due to residual stress gradient (fall color).
$\mathrm{SiC}$ cantilever. As a result, the bending moment caused by stress gradient is given by: $M=2 E I \delta / l^{2}$. Figure 3 shows a large out-of-plane deflection of a $\mathrm{SiC}$ cantilever due to residual stress gradient observed in a Focused Ion Beam (FIB) equipment with a tilt angle of $60^{\circ}$. From the deflection of $24 \mu \mathrm{m}$, the dimensions of the cantilever of 200 $\mu \mathrm{m} \times 5 \mu \mathrm{m} \times 0.3 \mu \mathrm{m}$, and the $\mathrm{SiC}$ Young's modulus of $350 \mathrm{GPa}$, the bending moment is estimated to be $5 \mu \mathrm{N}$. $\mu \mathrm{m}$. Consequently, this relatively large bending moment exerted on the micro frames in nano strain-amplifier would cause a large vertical displacement, and thus results in a large tensile strain in the bridging nano-spring.

Figure 4(a) shows the fabrication process of the proposed devices. For the proof of concept, we used a spring structure since it offers a lower spring constant in comparison to nanowires with the same width and thickness. The use of long $\mathrm{SiC}$ springs also allows a direct measurement of strain using a typical SEM. Initially, silicon carbide micro structures were patterned using inductive coupled plasma etching $\left(\mathrm{HCl}+\mathrm{O}_{2}\right)$ with an etching rate of approximately $100 \mathrm{~nm} / \mathrm{min}^{36}$. The $\mathrm{SiC}$ bridges were then released from the substrate by under-etching $\mathrm{Si}$ using $\mathrm{TMAH}$ at $90^{\circ} \mathrm{C}$ for approximately 1 hour (step 1). The width of the bridges was fixed at $5 \mu \mathrm{m}$, while their length was varied from 100 $\mu \mathrm{m}$ to $500 \mu \mathrm{m}$. Consequently, $\mathrm{SiC}$ nano-springs and supporting wires were then formed at the middle of the bridge using focused ion beam $\left(\mathrm{Ga}^{+}\right)$(step 2) ${ }^{37}$. The length of the spring was $27.71 \mu \mathrm{m}$, and the cross-sectional area was 294 $\mathrm{nm} \times 300 \mathrm{~nm}$. Finally, the supporting wires was removed by FIB (step 3), releasing the nano-spring.

Figure 4(b) shows the SEM image of suspended $\mathrm{SiC}$ bridges prior to releasing the nano-spring. Evidently, the bridges were in almost flat shape, indicating a uniform strain contributing along its longitudinal direction. Figure 4(c) presents the SEM image of the nano-spring after removing the supporting wires. The micro cantilevers on each side of the bridge were deflected vertically, leading to a large displacement in the nano-spring. Furthermore, the cantilevers were bent downward, indicating that a large compressive stress distributed at the bottom layer with respect to that of the top layers, Fig. 4(d). This result was in good agreement with the TEM observation mentioned above. Interestingly, because the two cantilevers were deflected at almost the same degree, the nano-spring remained in the lateral plane. Therefore, the length of the nano-spring can be accurately measured from the top view SEM image. In addition, as shown in Figure 4(e), to represent the visibility of large strains induced using the proposed structure, we fabricated a pair of nano springs in which one was completely released (top), while the other once was supported on both sides using two micro wires (bottom). Accordingly, a significant increase in the length of the nano spring was observed after removing the supporting wires. Let $L$ and $\Delta L$ be the initial length and the elongation of the nano spring observed using SEM, respectively, the induced strain is estimated to be: $\varepsilon=\Delta L / L$.

Figure 5 plots the strain in $\mathrm{SiC}$ nano-springs against the ratio between the length of the nano-spring to that of the suspended bridge $\left(L_{n s} / L_{f}\right)$. A strain of $7.6 \%$ in the $\mathrm{SiC}$ nano-spring was observed when $L_{n s} / L_{f}$ was 0.055 , which 

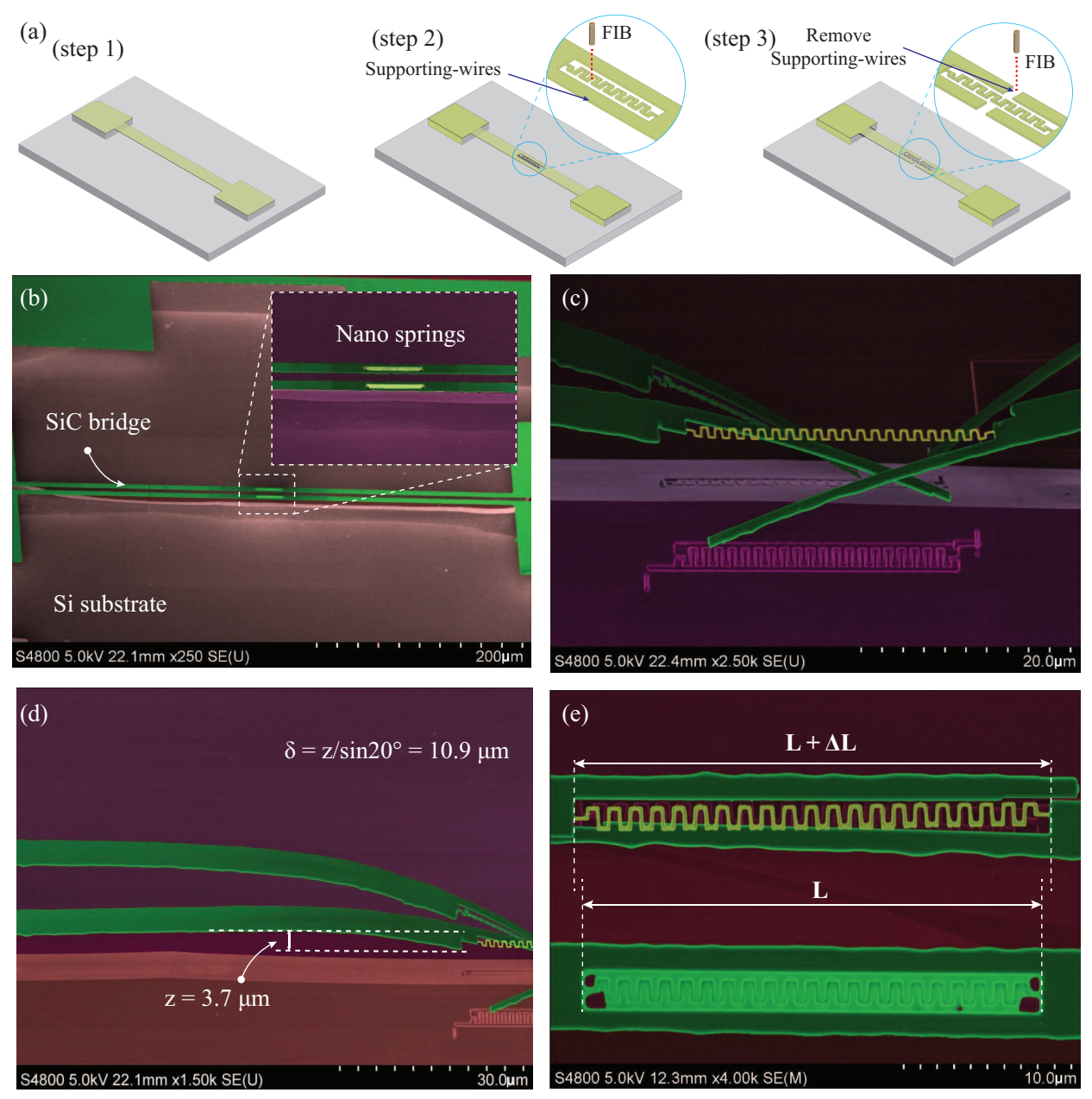

FIG. 4. Fabrication and SEM images of SiC nano-springs. (a) Fabrication process; (b) Suspended SiC bridge with nano-spring fabricated at the center (prior to removing the supporting wires); (c) SiC nano-springs after cutting the supporting wires; (d) Deflection of micro frame (or cantilever) on each side; (e) The elongation of the nano-spring observed from the top view.

is the largest strain reported in $\mathrm{SiC}$ so far. Additionally,

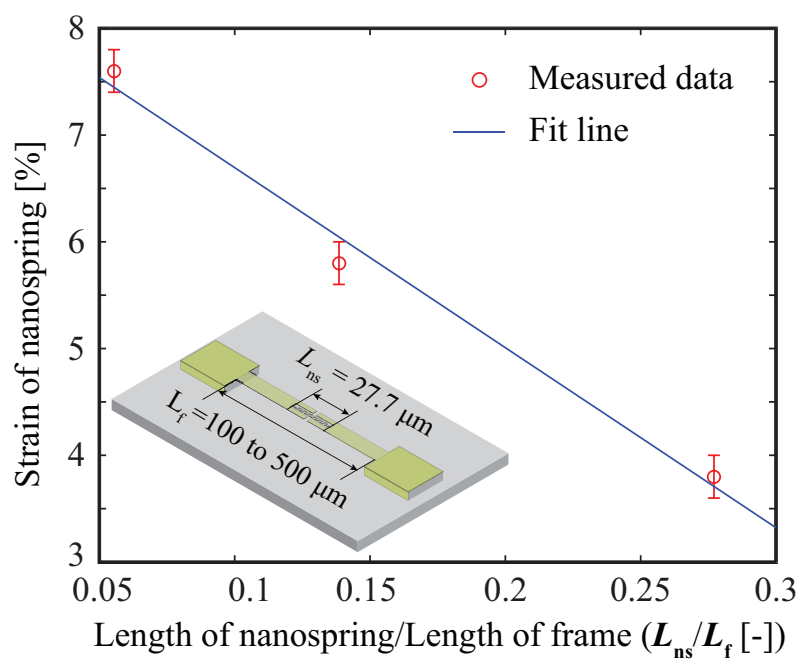

FIG. 5. Strain in $\mathrm{SiC}$ nano-springs with different $L_{n s} / L_{f}$ ratios. For the same $L_{n s}$, increasing the length of the $\mathrm{SiC}$ bridge $L_{f}$ leads to an increase in the strain of the nano-spring. increasing the $L_{n s} / L s$ results in a decrease in the applied strain, which is in solid agreement with Eq. 2 and Eq. 3. More importantly, the dependence of the strain of the nano-spring on $L_{n s} / L_{f}$ indicates that ultra-high strain is controllable by changing the device dimensions. This could be applied to tune the resonant frequency in $\mathrm{SiC}$ nano resonators.

Another interesting property in our nano-strain amplifier is that the strain was only concentrated in the locally formed nano-spring, while the micro frame (i.e. the $\mathrm{SiC}$ cantilever on each side of the bridge) can be almost freely deformed to release the residual stress. It means that the strain can be solely amplified at interested segments, retaining initially small strain in others. Therefore, the proposed structure can be applied to locally induce extremely high strain into 2D materials such as graphene or transition metal dichalcogenide, where the Van der Walls adhesion force between them and the substrate (e.g. Si, PDMS, glass) typically cannot withstand $1 \%$ strain $^{38-41}$. It should also be pointed out that as 2D materials typically have only a few atomic layers, the stress gradient is expected to be negligible. Therefore, the strain amplification in these materials is considered to be dominated by the in-plane compression of micro frames with respect to locally fabricated 
nano structures, as described in Eq. 2. The capability of inducing ultra-high residual strains into 2D materials could open up promising possibilities for the development of high frequency and high $\mathrm{Q}$ factor nano resonators ${ }^{42-44}$.

In conclusion, this work presents a mechanical approach to apply extremely large strain to $\mathrm{SiC}$ utilizing a nano strain-amplifier and the residual stress. We demonstrated an extremely high strain up to nearly $8 \%$ in a $\mathrm{SiC}$ nanospring structure. The proposed platform shows its potential for further investigations into the physics of $\mathrm{SiC}$ nano structures in high strain regimes, as well as the development of high frequency, high $\mathrm{Q}$ factor, and ultra-sensitive $\mathrm{SiC}$ mechanical sensors.

\section{Acknowledgment}

This work was partially funded by the linkage grant (LP150100153) from the Australian Research Council (ARC). This work was performed in part at the Queensland node of the Australian National Fabrication Facility, a company established under the National Collaborative Research Infrastructure Strategy to provide nano and microfabrication facilities for Australia's researchers.

${ }^{1}$ Si, C., Sun, Z., Liu, F. Nanoscale 2016, 8(6), 3207-3217.

${ }^{2}$ Zhang, Y., Liu, C., Liu, J., Xiong, J., Liu, J., Zhang, K., Liu, Y., Peng, M., Yu, A., Zhang, A., Zhang, Y., Wang, Z., Zhai, J., Wang, Z. L., ACS Appl. Mater. Interface 2016, 8(2), 1381-1387.

${ }^{3}$ Niquet, Y. M., Delerue, C., Krzeminski, C. Nano Lett. 2012, 12(7), 3545-3550.

${ }^{4}$ Bedell, S. W., Khakifirooz, A., Sadana, D. K. MRS Bulletin 2014, 39(02), 131-137.

${ }^{5}$ Feng, X. L., He, R., Yang, P., Roukes, M. L. Nano Lett. 2007, 7(7), 1953-1959.

${ }^{6}$ Zalalutdinov, M. K., Robinson, J. T., Junkermeier, C. E., Culbertson, J. C., Reinecke, T. L., Stine, R., Snow, E. S. Nano Lett. 2012, 12(8), 4212-4218.

${ }^{7}$ Witkamp, B., Poot, M., van der Zant, H. S. Nano Lett. 2006, 6(12), 2904-2908.

${ }^{8}$ Karabalin, R. B., Villanueva, L. G., Matheny, M. H., Sader, J. E., Roukes, M. L. Phys. Re. Lett. 2012, 108(23), 236101.

${ }^{9}$ Phan, H.-P.; Dao, D. V.; Nakamura, K.; Dimitrijev, S.; Nguyen, N.-T. J. Microelectromech. Syst. 2015, 24(6), 1663-1677.

${ }^{10}$ Senesky, D. G.; Jamshidi, B.; Cheng, K.B.; Pisano, A. P. IEEE Sensors J., 2009, 9(11), 1472-1478.

${ }^{11}$ Matsuda, Y., Kim, N., King, S. W., Bielefeld, J., Stebbins, J. F., Dauskardt, R. H. ACS Appl. Mater. Interfaces 2013, 5(16), 79507955.

${ }^{12}$ Brueckner, K., Niebelschuetz, F., Tonisch, K., Foerster, Ch., Cimalla, V., Stephan, R., Pezoldt, J., Stauden, T., Ambacher, O., Hein, M. A., Phys. Status Solidi a 2011, 208(2), 357-376.

${ }^{13}$ A. Qamar, H.-P. Phan, D. V. Dao, P. Tanner, T. Dinh, L. Wang, S. Dimitrijev, Electron Device Letters 2015, 36(7), 708-710.

${ }^{14}$ Gao, F.; Zheng, J.; Wang, M.; Wei, G.; Yang, W. Chem. Comm. 2011, 47(43), 11993-11995.

${ }^{15}$ D. V. Dao, H.-P. Phan, A. Qamar, T. Dinh, $R S C A d v$. 2016, 6(26), 21302-21307.

${ }^{16} \mathrm{Bi}$, J.; Wei, G.; Wang, L.; Gao, F.; Zheng, J.; Tang, B.; Yang,
W. Highly sensitive piezoresistance behaviors of n-type $3 \mathrm{C}-\mathrm{SiC}$ nanowires. J. Mater. Chem. C 2013, 1(30), 4514-4517.

${ }^{17}$ Zhang, N., Lin, C. M., Senesky, D. G., Pisano, A. P. TAppl. Phys. Lett. 2014, 104(7), 073504.

${ }^{18}$ Dinh, T.; Phan, H.-P.; Kozeki, T.; Qamar, A.; Namazu, T.; Nguyen, N.-T.; Dao, D. V. RSC Adv. 2015, 5, 106083-106086.

${ }^{19}$ Rao, S., Pangallo, G., Pezzimenti, F., Della Corte, F. G. Electron Device Lett. 2016, 36(7), 720-722.

${ }^{20}$ Dinh, T.; Dao, D. V.; Phan, H.-P.; Wang, L.; Qamar, A.; Nguyen, N.-T.; Tanner, P.; Rybachuk, M. Appl. Phys. Exp. 2015, 8(6), 061303, 2015.

${ }^{21}$ Phan, H. P., Dinh, T., Kozeki, T., Nguyen, T. K., Qamar, A., Namazu, T., Nguyen, N.-T., Dao, D. V. IEEE Electron Device Lett. 2016, 37(8), 1029-1032.

${ }^{22}$ Huang, X. M. H., Zorman, C. A., Mehregany, M., Roukes, M. L. Nature 2003, 421(6922), 496-496.

${ }^{23}$ Kermany, A. R., Brawley, G., Mishra, N., Sheridan, E., Bowen, W. P., Iacopi, F. Appl. Phys. Lett. 2014, 104(8), 081901.

${ }^{24}$ Wang, Z., Lee, J., Feng, P. X. L. Nature Comm. 2014, 5, 5158

${ }^{25}$ Kozeki, T., Phan, H. P., Dao, D. V., Inoue, S., Namazu, T. Jpn. J. Appl. Phys. 2016, 55(6S1), 06GL02.

${ }^{26}$ Snead, L. L., Hay, J. C. J. Nuclear Mater. 1999, 273(2), 213-220.

${ }^{27}$ Rohmfeld, S., Hundhausen, M., Ley, L., Zorman, C. A., Mehregany, M. J. Appl. Phys. 2002, 91, 1113-1117.

${ }^{28}$ Capano, M. A., Kim, B. C., Smith, A. R., Kvam, E. P., Tsoi, S., Ramdas, A. K. R J. Appl. Phys. 2006, 100(8), 083514.

${ }^{29}$ Anzalone, R., Alberti, A., La Via, F. Mater. Lett. 2014, 118, 130133.

${ }^{30}$ Colston, G., Rhead, S. D., Shah, V. A., Newell, O. J., Dolbnya, I. P., Leadley, D. R., Myronov, M. Mater. Design 2016, 103, 244-248.

${ }^{31}$ Falvo, M. R., Clary, G. J., Taylor, R. M., Chi, V., Brooks, F. P., Washburn, S., Superfine, R. Nature 1997, 389(6651), 582-584.

${ }^{32}$ Fei, R., Yang, L. Nano Lett. 2014, 14(5), 2884-2889.

${ }^{33}$ Tong, L., Mehregany, M., Matus, L. G. Appl. Phys. Lett. 1992, 60(24), 2992-2994.

${ }^{34}$ Kermany, A. R., Iacopi, F. J. Appl. Phys. 2015, 118(15), 155304.

${ }^{35}$ Phan, H.-P.; Qamar, A.; Dao, D. V.; Dinh, T.; Wang, L.; Han, J.; Tanner, P.; Dimitrijev, S.; Nguyen, N.-T. RSC Adv. 2015, 5, 56377-56381.

${ }^{36}$ Phan, H. P., Dinh, T., Kozeki, T., Qamar, A., Namazu, T., Dimitrijev, S., Nguyen, N.-T., Dao, D. V. Scientific Reports. 2016, 6, 28499.

${ }^{37}$ Phan, H. P., Dinh, T., Kozeki, T., Nguyen, T. K., Qamar, A., Namazu, Nguyen, N.-T., Dao, D. V. Appl. Phys. Lett. 2016, 109(12), 123502.

${ }^{38}$ Perez-Garza, H. H., Kievit, E. W., Schneider, G. F., Staufer, U. H Nanotechnology 2014, 25(46), 465708.

${ }^{39}$ Rostami, H., Roldan, R., Cappelluti, E., Asgari, R., Guinea, F. Phys. Rev. B 2015, 92(19), 195402.

${ }^{40}$ Tao, J., Shen, W., Wu, S., Liu, L., Feng, Z., Wang, C., Hu, C., Yao, P., Zhang, H., Pang, W., Duan, X., Liu, J., Zhou, C, Zhang, D., ACS nano 2015, 9(11), 11362-11370.

${ }^{41}$ Plechinger, G., Castellanos-Gomez, A., Buscema, M., van der Zant, H. S., Steele, G. A., Kuc, A., Heine, T. Schuller, C., Korn, T. $2 D$ Materials 2016, 2(1), 015006.

${ }^{42}$ Shivaraman, S., Barton, R. A., Yu, X., Alden, J., Herman, L., Chandrashekhar, M.V.S., Park, J., McEuen, P.L., Parpia, J.M., Craighead, H.G., Spencer, M.G., Nano Lett., 2009, 9(9), 31003105.

${ }^{43}$ Takamura, M., Furukawa, K., Okamoto, H., Tanabe, S., Yamaguchi, H., Hibino, H., Jpn. J. Appl. Phys., 2013, 52(4S), $04 \mathrm{CH} 01$.

${ }^{44}$ Oshidari, Y., Hatakeyama, T., Kometani, R., Warisawa, S.I. and Ishihara, S., Appl. Phys. Express, 2012, 5(11), 117201. 